\title{
MECANISMO DE VÁLVULA GAVETA - R SERIES*
}

\author{
Maurício dos Santos ${ }^{1}$ \\ Fabricio Junior Silva ${ }^{2}$ \\ Yokoi Nobuyuki \\ Imahase Toshihiro ${ }^{4}$
}

\section{Resumo}

Através desta nova tecnologia para mecanismos de válvula gaveta de panela, estamos apresentando um novo conceito de trabalhabilidade, reduzindo o esforço físico do homem, através de um equipamento simples, robusto e de fácil manuseio dos refratários durante as trocas de placas e válvulas.Com este novo conceito para abertura e fechamento do mecanismo, reduzimos de forma expressiva o número de atividades do operador e com isso reduzimos o tempo para liberação da panela, proporcionando para a aciaria, uma maior disponibilidade de equipamento e certamente menor tempo de parada ou perda de sequencial durante a troca dos refratários. Considerando um projeto mais robusto, com menor número de peças sobressalentes, conseguimos reduzir de forma expressiva, o custo de manutenção deste mecanismo, visto que a deformação ou desgaste das peças deste equipamento estão dimensionados para suportar as mais adversas condições operacionais de uma usina siderúrgica. Através de um sistema de molas altamente preciso, garantimos uma pressão uniforme dos refratários, garantindo total segurança durante o processo de lingotamento contínuo, porém com um grande diferencial de segurança, quando comparado a outras tecnologias de mecanismos, ou seja, através de um sistema visual (GAP), o operador poderá avaliar a cada corrida, as condições gerais do equipamento (desgaste, deformação, irregularidades, etc.), tomando a decisão de afastar ou não o mecanismo, antes de liberá-lo para próxima corrida, garantindo assim, uma total segurança do homem e equipamento.

Palavras-chaves: Mecanismo de Válvula Gaveta; Mecanismo para Controle de Fluxo; Lingotamento Contínuo.

\section{NEW LADLE SLIDE GATE - R SERIES}

\section{Abstract}

This paper presents a revolutionary development of a Ladle Slide Gate Mechanism - R Series, a robust equipment, safer for steel flow control from the ladle to the tundish. The simplified structure, dual frame design, eliminates unnecessary parts providing simple and stable operation. With a friendly operation, the standard tools required for face pressure loading and plate clamping can be eliminated or reduced.

The R Gate eliminates the need of a suspending frame. It simplifies the basic structure consisting of the upside frame and slide frame. This results in a slide gate design which provides simple, consistent daily operation. The latches allow the upper and lower plates to be set in a single action. A combination of the fitting boss in the frame, and the positioning windows cut in the steel back plate ensures the correct location of the plate brick in each frame.The pressure between plates is safer, considering two coil spring box located on each side of the upside frame, that provides more resistance and guarantee the elimination of any steel infiltration. This mechanism has been successfully used in a medium size ladle (150 ton) in a Brazilian Steel Company.

Keywords: Ladle Slide Gate; Flow Control Mechanism; Ladle Gate; Continuous Casting; Slide Gate Mechanism.

Especialista Global de Desenvolvimento, Flow Control Mechanism, Magnesita Refratários S.A., Belo Horizonte, MG, Brasil.

2 Engenheiro de Projetos, Flow Control Mechaism, Magnesita Refratário S.A., Belo Horizonte, MG, Brasil.

3 Engenheiro de Desenvolvimento, Flow Control Mechanism, Krosaki Harima Corporation, Kitakyushu, Fukuoka, Japão.

4 Engenheiro de Projetos, Flow Control Mechanism, Krosaki Harima Corporation, Kitakyushu, Fukuoka, Japão. 


\section{INTRODUÇÃO}

Historicamente, mecanismos de válvula gaveta robustos, com alta força de compressão entre as placas refratárias (resultante da utilização de molas helicoidais), são as principais características para os mecanismos de controle de fluxo do aço liquido, desenvolvidos pela Krosaki Harima Corporation (KHC).

A Magnesita Refratários S.A. (MRSA) em conjunto com a Krosaki Harima Co. desenvolveu um novo sistema de válvula gaveta ( $R$ Series) o qual executa de forma simples e rápida, a compressão / descompressão das molas e troca de placas na preparação de panelas, obtendo diversos benefícios.

Além disso, o formato das placas refratárias foi desenvolvido, baseado em estudos realizados através de simulações numéricas com o objetivo de minimizar a formação de trincas e certamente melhorar e ergonomia do operador.

Nesse trabalho são discutidos alguns detalhes técnicos a respeito desse novo sistema ( $R$ Series), vantagens decorrentes da sua utilização, principalmente no que tange à trabalhabilidade operacional e aspectos de segurança (ergonomia) e com relação aos refratários, são apresentados resultados de performance reais.

\subsection{Concepção Básica do Novo Sistema de Válvula Gaveta (R Series)}

O novo sistema de válvula gaveta $\mathrm{R}$ Series, foi projetado de modo a garantir sempre a segurança operacional e a diminuir o esforço exercido pelo operador durante a troca dos refratários que compõem o sistema.

Abaixo são citadas as principais vantagens que o sistema oferece:

> 02 alternativas para se efetuar a compressão entre placas, podendo optar pelo sistema automático ou hidráulico (dependendo do layout de cada cliente). Nos mecanismos convencionais necessita-se da utilização de chaves pneumáticas e mangueiras para compressão e descompressão das molas;

> Ajuste das placas refratárias sem a necessidade de parafusos, com objetivo de agilizar a operação de troca das placas, garantir o perfeito posicionamento e principalmente, aumentar a segurança operacional, reduzindo o tempo de exposição do homem à temperatura do fundo da panela;

> Sem a necessidade de troca da chapa de base, ou seja, o mecanismo $R$ Series é adaptável em quase todos os tipos chapas de base (outros mecanismos) agilizando assim o proceso de teste e implantação do mecanismo, reduzindo as atividades e o tempo de intervenção no fundo da panela;

> Utiliza o conceito de afastamento do mecanismo do fundo da panela, visando minimizar o impacto da temperatura e deformação no mecanismo, o que permite uma refrigeração do sistema durante o lingotamento;

$>$ Referencial (GAP) para inspeção do mecanismo a cada corrida, ou seja, através de um referencia visual o operador poderá identificar irregularidades no mecanismo, afastando o mesmo de operação, garantindo assim total segurança para o homem e equipamento.

As figuras 1 e 2 mostram o Mecanismo de Válvula Gaveta R Series. 


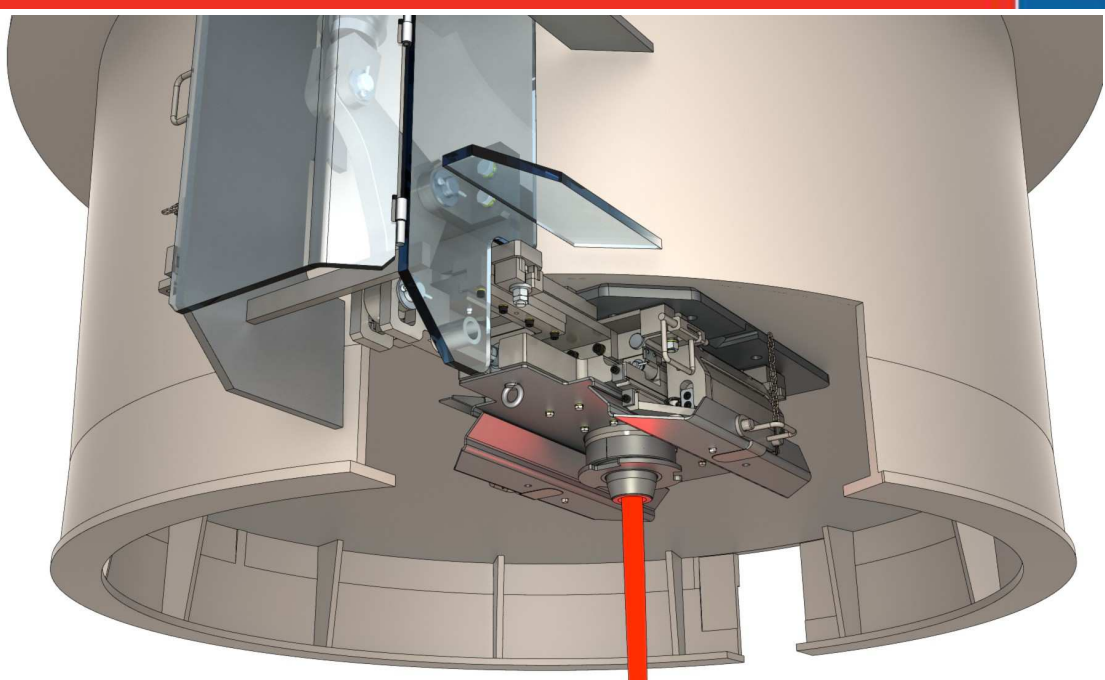

Figura 1: Mecanismo de Válvula Gaveta R Series

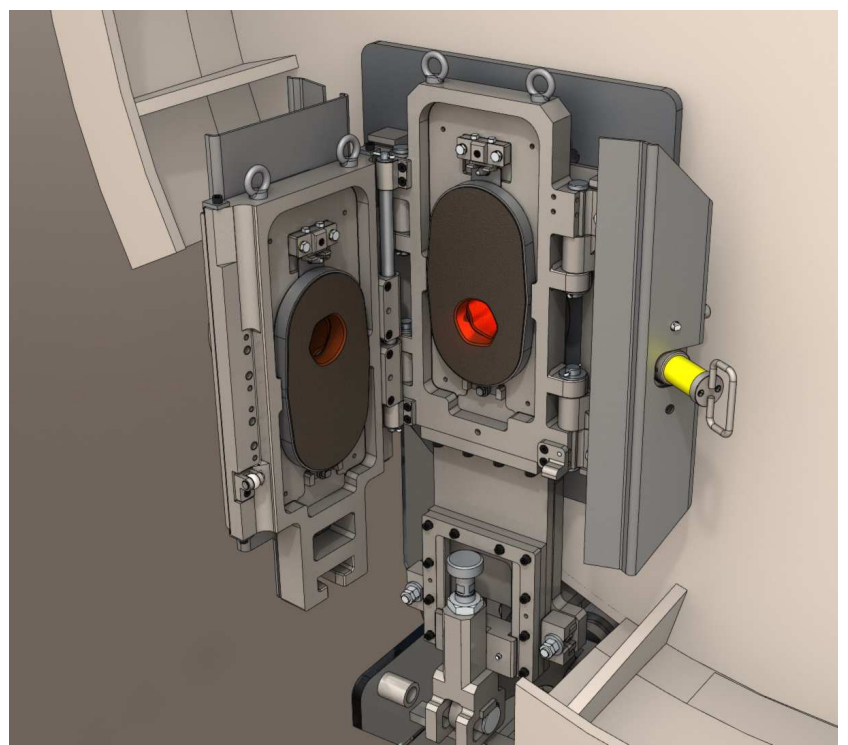

Figura 2: Mecanismo aberto em posição de troca de placas.

\subsection{Carregamento Automático do Sistema de Compressão das Molas}

> Um importante avanço do R Series é a utilização do próprio mecanismo para aplicação da carga entre placas refratárias, através de um conjunto de planos inclinados e o próprio cilindro hidráulico de acionamento. Este processo é chamado de carregamento automático.

> Os planos inclinados são situadas em ambos os lados do quadro móvel (nas corrediças), como também nas corrediças, situadas nas caixas de molas helicoidais, posicionadas em ambos os lados do quadro superior. Como mostra a figura 3 , os planos inclinados, quando coincidentes exercem a descompressão das molas e quando sobrepostos exercem a compressão do sistema, ou seja, garantem a pressão entre placas.

> Quando o quadro móvel é acionado pelo cilindro hidráulico, os planos inclinados deslizam entre si e conseqüentemente, as molas helicoidais são comprimidas. 
$>$ Este mecanismo, relativamente simples, converte a força transmitida pelo cilindro hidráulico (utilizado na abertura e fechamento das placas) em força de compressão das molas helicoidais, sendo que o trabalho manual exercido pelo operador é sensivelmente reduzido, limitando-se a fechar as 02 caixas de molas e acionar o cilindro hidráulico através de uma botoeira.

\section{Easier}

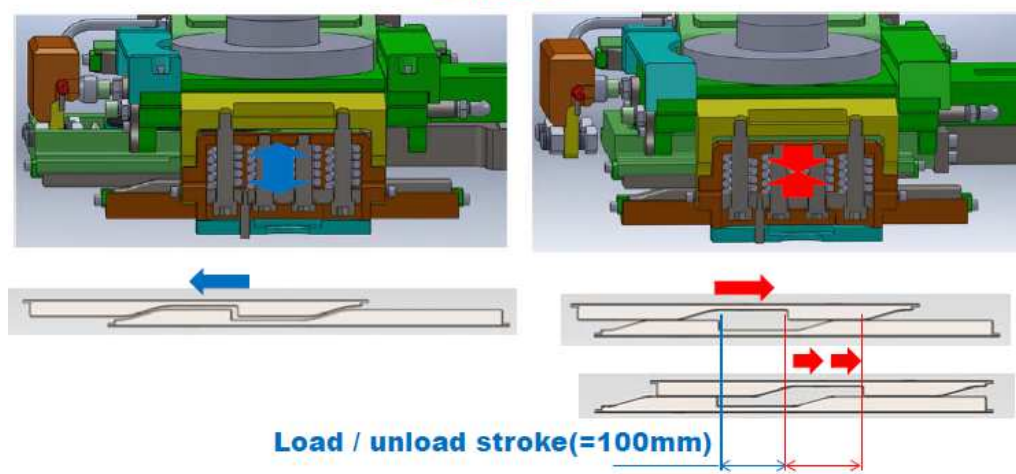

Figura 3: Posicionamento das corrediças na compressão e descompressão das molas.

\subsection{Carregamento Hidráulico do Sistema de Compressão das Molas}

> Um importante avanço do R Series é a alternativa de utilização de 02 cilindros hidráulicos para aplicação da carga entre placas refratárias, através de um sistema hidráulico portátil e compacto. Este processo é chamado de carregamento hidráulico.

$>$ Os cilindros são montados na lateral das caixas de molas helicoidais, posicionadas em ambos os lados do quadro superior (figuras 4 e 5).
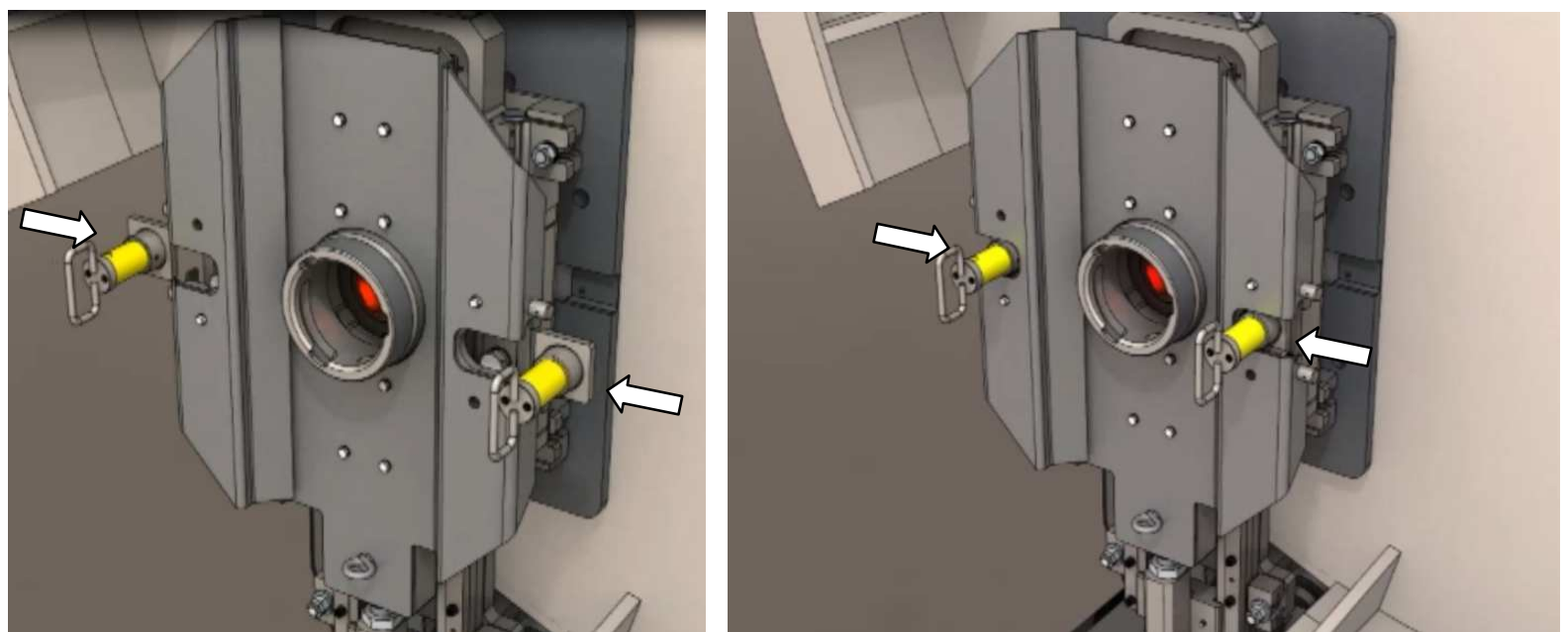

Figura 4 e 5: Posicionamento dos cilindros nas caixas de molas.

Como mostra a figura 6 e 7, os cilindros exercem a descompressão das molas quando acionado, permitindo a aberturada das caixas de molas e consequentemente a abertura do quadro móvel. Quando a pressão do cilindro é aliviada, o mesmo pode ser retirado e a pressão entre placas esta garantida pelo sistema de molas. 

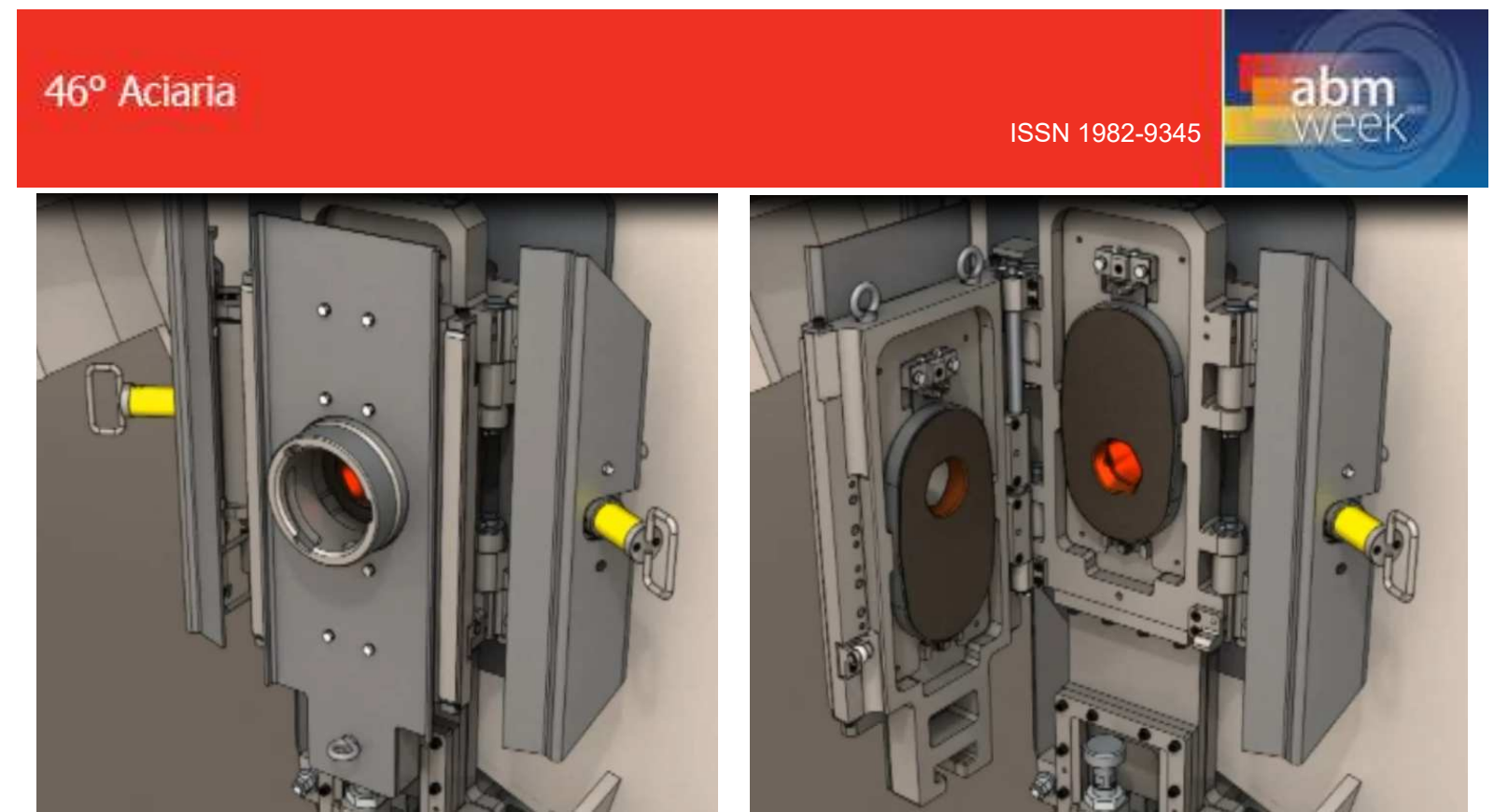

Figura 6 e 7: Abertura das caixas de molas e quadro móvel.

$>$ Este conceito, relativamente simples, converte a força transmitida pelos cilindros hidráulicos (unidade portátil) em força de compressão das molas helicoidais, sendo que o trabalho manual exercido pelo operador é sensivelmente reduzido, limitando-se a montagem dos cilindros, fechamento das 02 caixas de molas e acionamento dos cilindros hidráulicos, através de uma botoeira.

\subsection{Sistema de Segurança}

> Sabendo-se que parte do procedimento da preparação da panela, antes da sua liberação para operação é a movimentação do mecanismo entre as posições totalmente aberto e fechado, o operador poderá perceber, durante esta verificação, que as molas foram comprimidas através do referencial do GAP, que sinaliza para o operador a qualidade do trabalho efetuado, garantindo que o mecanismo não será liberado fora de especificação, conforme ilustram as figuras 8,9 e 10.
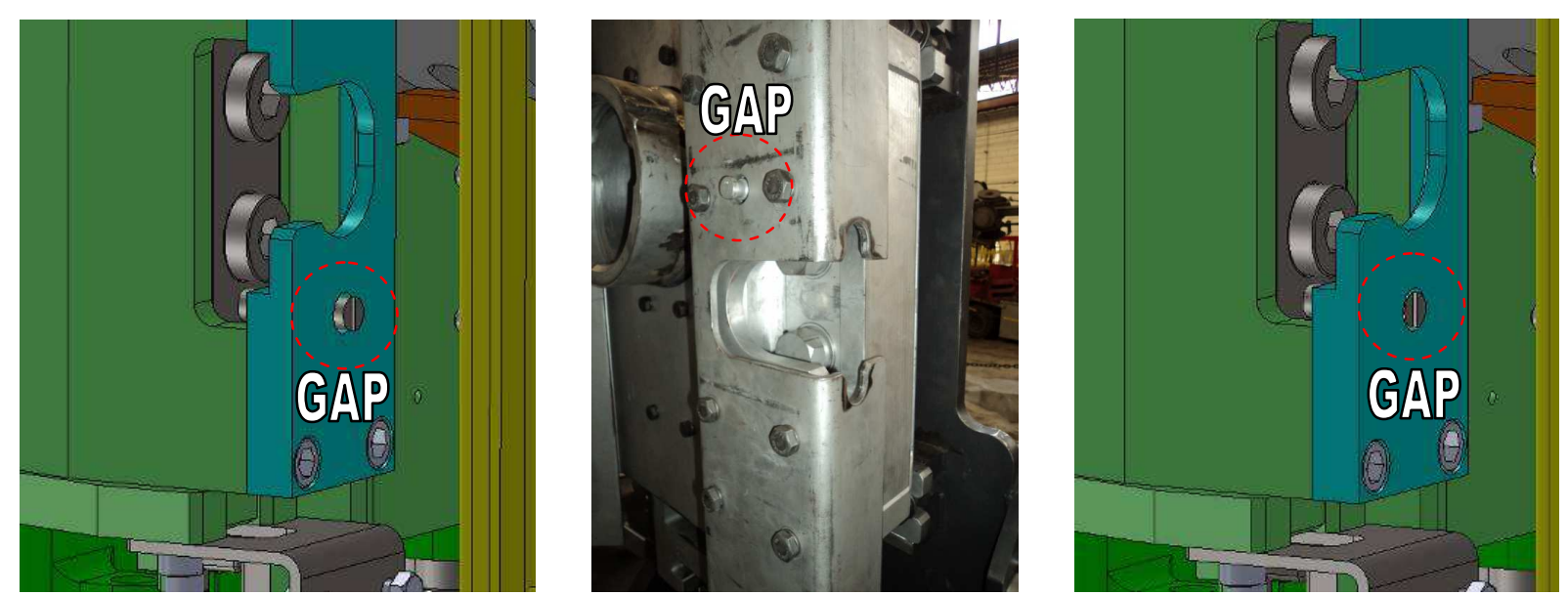

Figura 8, 9 e 10: Referencial do GAP para liberação do mecanismo

\subsection{Formato Otimizado das Placas}

A principal causa da geração de trincas em placas de válvula gaveta é o aparecimento de tensões de tração ao redor do furo. Para evitar o surgimento destas 
tensões, as placas são cintadas a quente, garantindo um aperto uniforme em todo perímetro da placa.

Com o objetivo de minimizar o aparecimento destas tensões de tração, foi desenvolvido pela Krosaki Harima Co. um estudo utilizando a técnica de elementos finitos e simulação numérica, de forma a otimizar o formato das placas.

A figura 11 mostra a placa com o formato convencional e a placa com o formato otimizado para o mecanismo $\mathrm{R}$ Series. Conforme se pode verificar, a placa com formato otimizado possui cantos arredondados. Além disso, este estudo demonstrou que o local onde é exercida a pressão das cunhas na lateral da placa, exerce grande influência nas tensões geradas. Definiu-se, portanto, para o novo mecanismo, que eliminando estas áreas de contato, teríamos menor tensão e trincas no refratário, geradas em muitos casos pelo excesso de aperto do operador.
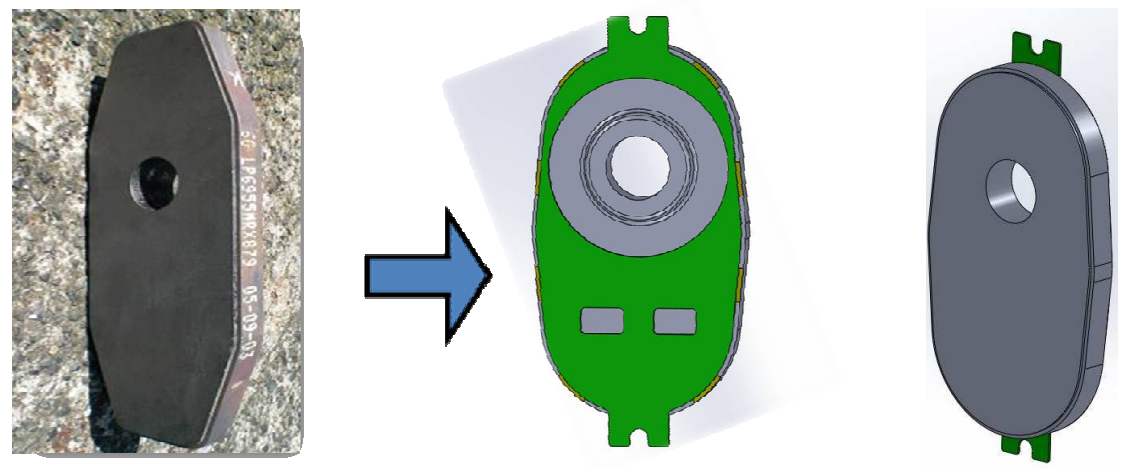

Figura 11 : Placas com formato convencional e otimizado (Mecanismo R Series)

A figura 12 apresenta os resultados de tensão obtidos ao longo da placa sob duas condições: (A) após o cintamento e (B) após aquecimento em operação.

Conforme pode ser observado na figura 12, não há diferenças significativas de tensão entre os dois formatos de placa quando submetidos à condição $(A)$. Contudo, quando posteriormente são submetidas à condição $(B)$, a placa com formato otimizado apresenta resultados de tensão menores e sempre em estado de compressão, que é a melhor condição para evitar o aparecimento de trincas. 

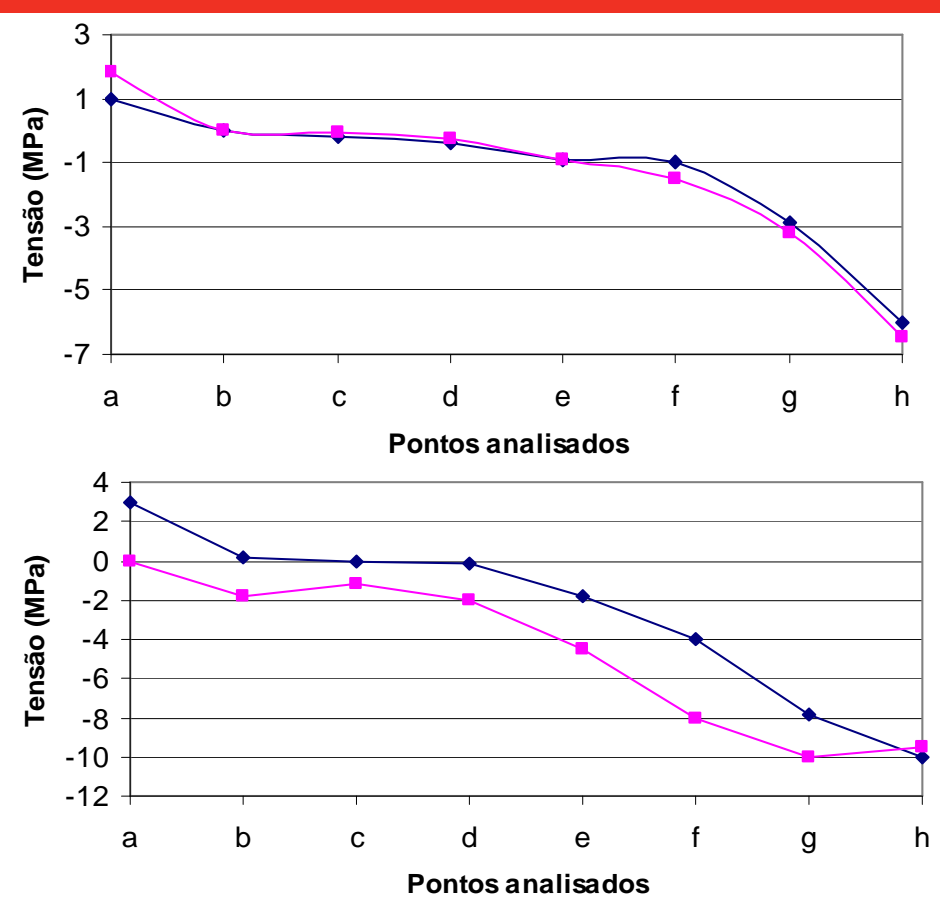

Figura 12: Análises de tensão realizadas $(A)$ após o cintamento das placas e $(B)$ após aquecimento das placas.

Durante o processo de seleção dos materiais de placas refratárias é necessário que haja um equilíbrio entre a resistência à erosão e o spalling. $O$ desenvolvimento da nova geometria do mecanismmo $\mathrm{R}$ Series permitirá a utilização de novos materiais refratários com maior resistência à erosão sem que haja, no entanto, prejuízo da resistência ao spalling.

\section{RESULTADOS E DISCUSSÃO}

Os resultados apresentados abaixo, foram obtidos durante operação do mecanismo em uma usina siderúrgica brasileira.

\subsection{Trabalhabilidade Operacional}

Foi observado, em levantamento de campo, que durante a operação de troca dos refratários que compõem o sistema de válvula gaveta, o tempo requerido para preparação do mecanismo $\mathrm{R}$ Series foi reduzido sensivelmente comparado-o com o sistema convencional.

As etapas monitoradas foram: limpeza com $\mathrm{O}^{2}$, abertura do mecanismo, troca das placas e fechamento do mecanismo. Com exceção da limpeza, as demais etapas apresentaram redução do tempo necessário para sua execução, sendo que o ganho total foi da ordem de $40 \%$. 
Atividades do Preparador de Panela

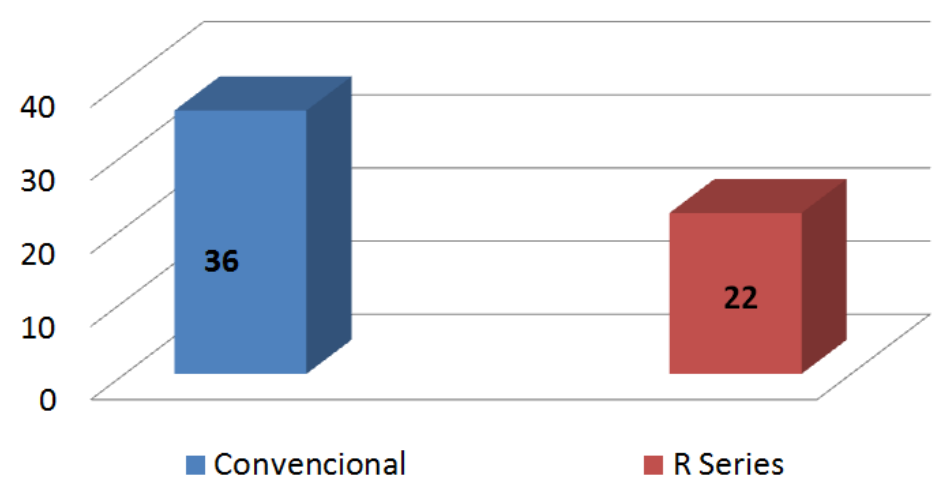

Figura 13: Redução de aproximadamente $40 \%$ do tempo de preparação da panela.

Os procedimentos e métodos utilizados para inspeção das superfícies das placas refratárias após abertura do sistema de válvula gaveta $R$ Series são os mesmos adotados nos sistemas convencionais, no entanto, os ganhos de tempo ocorreram principalmente devido à simplicidade do sistema de fechamento e abertura do mecanismo e principalmente o sistema de fixação das placas refratárias sem utilização de parafusos.

O novo sistema de válvula gaveta $\mathrm{R}$ Series agiliza a operação, reduz o tempo de troca dos refratários e possibilita que a operação de troca de placas seja realizada por uma única pessoa.

\subsection{Desempenho das Válvulas}

As válvulas superiores e inferiores utilizadas no sistema de válvula gaveta $R$ Series mantiveram as mesmas características das utilizadas no sistema convencional, dessa forma, mantiveram também o mesmo bom desempenho.

As figuras 14 e 15 mostram o desempenho das válvulas superiores e inferiores durante operação de quatro campanhas consecutivas de uma mesma panela.

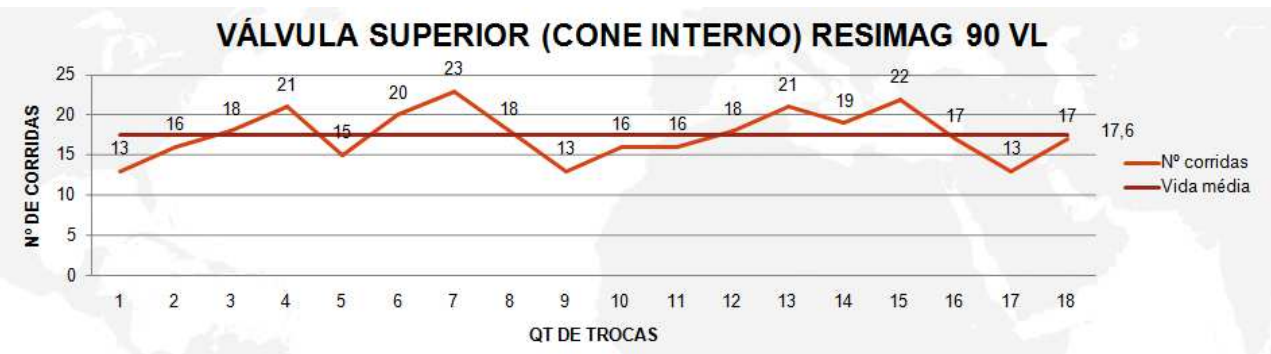

Figura 14: Performance das válvulas superiores no mecanismo $R$ Series.

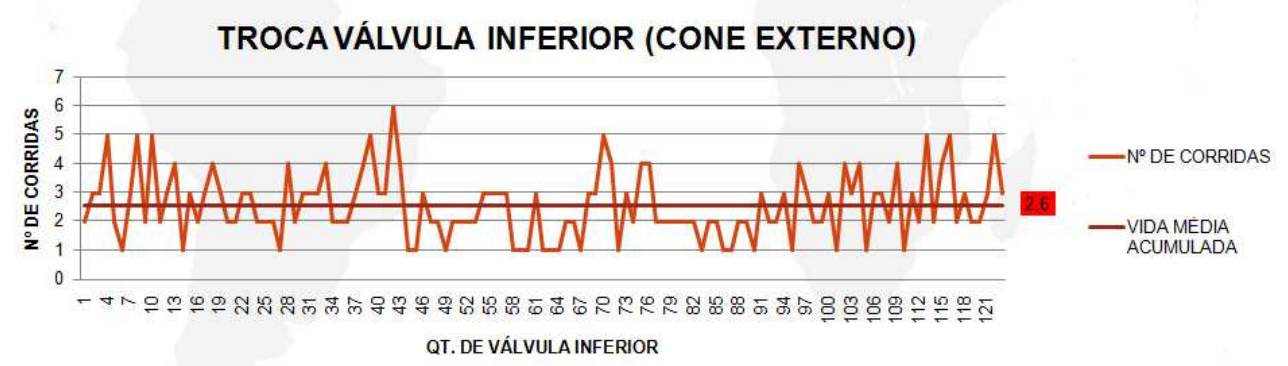

Figura 15: Performance das válvulas inferiores no mecanismo R Series. 


\subsection{Desempenho das Placas}

Assim como as válvulas, as placas utilizadas no sistema da $\mathrm{R}$ Series mantiveram as mesmas características das utilizadas no sistema convencional, porém com avanços na sua geometria com o objetivo de aumento da resistência à formação de trincas a partir da utilização de recursos de simulações numéricas (elementos finitos).

Observou-se que a nova geometria permitiu a obtenção de uma melhor distribuição de tensões e a conseqüente minimização da formação de trincas na região de trabalho das placas. Com isso, foram obtidos os mesmos resultados de performance das placas convencionais, no entanto, com um ganho na segurança operacional de todo o conjunto.

A figura 16 mostra as superfícies de contato das placas do mecanismo R Series com as superfícies isentas de trincas.
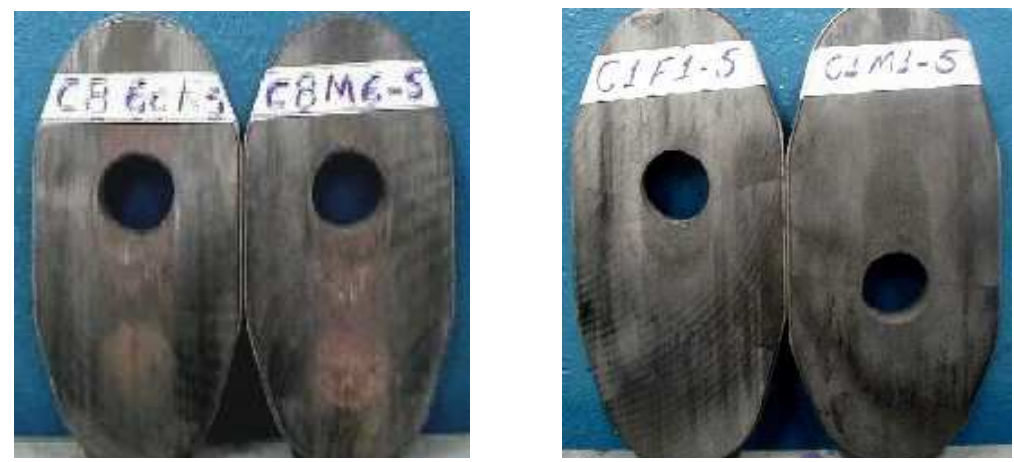

Figura 16: Placas utilizadas do mecanismo R Series.

A figura 17 mostra o desempenho das placas fixa e móvel durante operação de duas campanhas consecutivas de uma mesma panela.

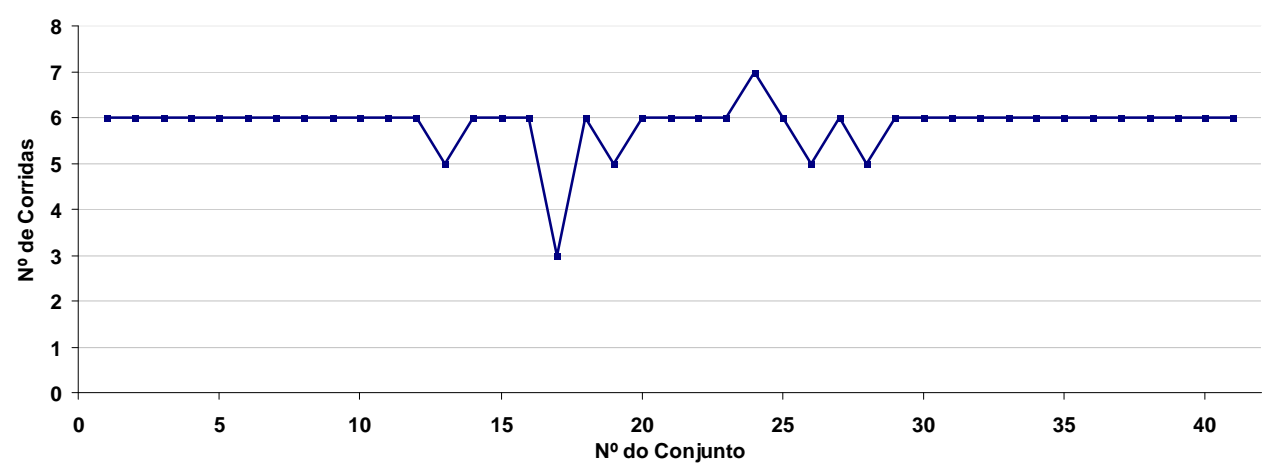

Figura 17: Performance das placas no mecanismo R Series.

O conjunto de placas retirado com apenas três corridas apresentava características normais, no entanto, a panela foi afastada por motivos operacionais.

\section{CONCLUSÃO}

A utilização de um sistema de válvula gaveta (mecanismo e refratários) adequado e bem dimensionado é de fundamental importância para atender às necessidades de um processo de lingotamento contínuo seguro, eficiente e com uma boa relação de custo e benefício.

Historicamente os mecanismos de válvula gaveta com know-how Krosaki Harima Co. têm como premissas o desenvolvimento de sistemas com elevada segurança 
operacional e alta performance dos componentes mecânicos e refratários. Essas características foram aprimoradas no Mecanismo R Series conforme descrito abaixo:

- Maior segurança operacional;

- Maior agilidade durante troca das placas refratárias, abertura e fechamento do mecanismo;

- Melhor ergonomia para os operadores;

- Projeto simplificado dos componentes mecânicos;

- Menor custo de manutenção;

- Projeto avançado visando reduzir a possibilidade de falhas;

- Formato das placas refratárias desenvolvido por análise de elementos finitos;

- Tecnologia e confiabilidade Krosaki Harima Corporation. 